\title{
Beneficial Effects of Commonly Used Phytochemicals in Diabetes Mellitus
}

\author{
Merve Bacanlı 1*, Hatice Gül Göktaş̧,2, Nurşen Başaran", \\ Nuray Arl ${ }^{3}$, A. Ahmet Başaran ${ }^{4}$ \\ ${ }^{1}$ Hacettepe University, Faculty of Pharmacy, Department of Pharmaceutical Toxicology, 06100, Ankara, Turkey \\ ${ }^{2}$ Çukurova University, Faculty of Pharmacy, Department of Pharmaceutical Toxicology, 01330, Adana, Turkey \\ ${ }^{3}$ Ankara University, Faculty of Pharmacy, Department of Pharmacology, 06100, Ankara, Turkey \\ ${ }^{4}$ Hacettepe University, Faculty of Pharmacy, Department of Pharmacognosy, 06100, Ankara, Turkey
}

\begin{abstract}
Diabetes mellitus, a metabolic disorder, is characterized by absolute or relative deficiencies in insulin secretion and/or insulin action associated with chronic hyperglycemia. The prevalence of diabetes is increasing worldwide, especially in developing countries. The diabetes treatment has higher costs, limited efficacy and side effects. As a result of these factors, patients often have used alternative forms of therapy such as herbal medicines. Plants often contain various amounts of phenolics, flavonoids and tannins and most of the studies are focused on the antidiabetic effects of these phytochemicals due to their antioxidant properties. In this review, the role of oxidative stress on diabetes and the effects of different phytochemicals (limonene, sinnamic acid and ursolic acid) to diabetes mellitus therapy will be discussed.
\end{abstract}

Keywords: limonene, cinnamic acid, ursolic acid, diabetes

\section{INTRODUCTION}

Diabetes mellitus, a metabolic disorder, is characterized by absolute or relative deficiencies in insulin secretion and/or insulin action associated with chronic hyperglycemia and disturbances of carbohydrate, lipid and protein metabolism ${ }^{1}$. Due to a higher incidence of the risk factors, the prevalence of diabetes is increasing worldwide, especially in developing countries ${ }^{2} .2 .8 \%$ of world population suffer from diabetes and it is concluded that it may cross $5.4 \%$ by the year of $2025^{3}$. In Turkey, $7.4 \%$ of population suffer from diabetes and also it is estimated

*Corresponding author: Merve Bacanlı

E-mail address: mervebacanli@gmail.com 
that the number of patients will be increased to $9.6 \%$ of population by the year of $2030^{2}$.

The studies on diabetes therapy have gained interest due to its unwanted effects on human life e.g. changing lifestyles lead to reduced physical activity, and increased obesity ${ }^{2}$. In diabetes treatment, the current drugs can be divided into three groups: (i) Sulphonylureas such as glibenclamide, the glinides, insulin analogs, glucagon-like peptide 1 (GLP-1) agonists and dipeptidyl peptidase-IV (DPP-IV) inhibitors can increase endogenous insulin availability, (ii) Thiazolidinediones, agonists of the peroxisome proliferatoractivated receptor gamma (PPARY) and the biguanide metformin can enhance the sensitivity of insulin, (iii) a-glucosidase inhibitors such as acarbose can reduce the digestion of polysaccharides and their bioavailability ${ }^{4,5}$. All of these drugs have higher costs, limited efficacy and tolerability and/or significant side effects ${ }^{6,7}$.

As a result of these factors, patients have often used alternative forms of therapy such as herbal medicines ${ }^{8}$. Especially, the herbal medicine usage for diabetes treatment is common in West Africa, Central America and Asia9, 10,11. According to an estimation published by the World Health Organization (WHO), approximately $80 \%$ of diabetic patients presently rely on herbal medicine for their successive treatments ${ }^{12}$. Traditional medicine is an accessible, affordable and culturally acceptable form of healthcare trusted by large numbers of people, which stands out as a way of coping with the relentless rise of chronic non-communicable diseases in the midst of soaring health-care costs and nearly universal austerity ${ }^{13}$. Unfortunately, pharmacological and toxicological evidences validating the safety and efficacy of these medicinal plants are not readily available ${ }^{14}$.

Plants often contain various amounts of phenolics, flavonoids and tannins. Most of the studies are focus on the antidiabetic effects of these phytochemicals due to their antioxidant properties ${ }^{15}$. For example, epidemiological studies have associated a diet rich in isoflavones with a lower risk of diabetes and diabetes related complications $^{16,17}$.

In this review, the role of oxidative stress on diabetes and diabetes mellitus therapy with different phytochemicals (limonene, cinnamic acid and ursolic acid) will be discussed.

\section{DIABETES, OXIDATIVE STRESS and ANTIOXIDANTS}

There are different types of diabetes. (i) Type 1 diabetes: This form of diabetes is also called insulin dependent diabetes mellitus (IDDM). When the pancreas produces insufficient amounts of insulin to meet the body's needs, this type of diabetes will occur. A trigger-either an illness or stress-causes the immune system 
to attack and destroy the beta cells of the pancreas. As a result, pancreas stops producing insulin. Type 1 develops suddenly in childhood or in adolescence. (ii) Type 2 diabetes: This form of diabetes is also called Non-Insulin Dependent Diabetes Mellitus (NIDDM). When the pancreas produces insulin, but the cells are unable to use it efficiently; this effect is called "insulin resistance". Type 2 diabetes is far more common than Type 1 and approximately $90 \%$ of all diabetes cases are Type 2. There is a strong genetic predisposition. Age, obesity and sedentary lifestyle are also risk factors. (iii) Gestational diabetes mellitus: Glucose intolerance being recognized during pregnancy. It can complicate pregnancy leading to prenatal morbidity and mortality3.

It is known that oxidative stress results from an imbalance between the generation of oxygen derived radicals and antioxidant system ${ }^{18}$. Numerous studies have shown that diabetes mellitus is associated with increased formation of free radicals and decrease in antioxidant potential. In both types of diabetes, oxidative stress is increased ${ }^{19}$.

Multiple factors can cause oxidative stress in diabetes. The most important factor is glucose autoxidation leading to the production of free radicals. Other factors include cellular oxidation/reduction imbalances and reduction in antioxidant defenses (including decreased cellular antioxidant levels and a reduction in the activity of enzymes that dispose of free radicals). Levels of some prooxidants such as ferritin and homocysteine are elevated in diabetes. Another important factor is the interaction of advanced glycation end products (AGEs) with specific cellular receptors called AGE receptors (RAGE). Elevated levels of AGE are formed under hyperglycemic conditions. Their formation is initiated when glucose interacts with specific aminoacids on proteins forming a compound that then undergoes further chemical reactions. Glycation of protein alters protein and cellular function, and binding of AGEs to their receptors can lead to modification in cell signaling and further production of free radicals ${ }^{20}$. The other nonenzymatic factors are activation of $\mathrm{NAD}(\mathrm{P}) \mathrm{H}$ oxidases, nitric oxide synthase, and a specific enzyme activity, xanthine oxidase, which produces oxidant species and subsequent oxidative stress ${ }^{21,22,23,24}$.

Numerous reports have documented elevations in peroxide levels in plasma, red blood cells and tissues of animals with chemically-induced diabetes ${ }^{25}$, 26 . Increases in blood peroxides or other indices of oxidative stress have also been reported in diabetic patients ${ }^{27}$. Both increases and decreases in the activities of key antioxidant enzymes including catalase (CAT), superoxide dismutase (SOD), glutathione peroxidase (GSH-Px), and glutathione reductase (GR) have been reported $^{28}$. In a pediatric study, antioxidant activity was found to be decreased in 
relation to poor glycemic control ${ }^{29}$. It is also shown that oxidative stress exists in diabetic patients as evidenced by increased total antioxidant capacity in saliva and blood of patients ${ }^{30}$.

The primary defense against oxidative stress in the cell, rests with antioxidants like vitamin $\mathrm{E}$, glutathione and peroxidases ${ }^{19}$. Antioxidants show their effects with different mechanisms. These mechanisms are: enzymes that degrade free radicals, proteins (e.g. transferrin) bind metals which stimulate the production of free radicals and antioxidants like vitamin $\mathrm{E}$ and $\mathrm{C}$ scavenge free radicals ${ }^{20}$.

Recently, there has been a growing interest in replacing synthetic diabetic drugs with natural antioxidants from plant materials. Studies have shown that plants contain a large variety of substances that possess antioxidant activity ${ }^{31}$. They can prevent the formation of advanced glycated end products (AGEs) and other diabetic complications associated with oxidative stress ${ }^{32}$. Phytochemicals with antioxidant effects include; cinnamic acids, coumarins, diterpenes, flavonoids, lignans, monoterpenes, phenylpropanoids, tannins and triterpenes ${ }^{33}$.

There are too many studies about the beneficial effects of phytochemicals on diabetes therapy. Arya et al. (2014) demonstrated that low dose quercetin and quinic acid showed protective effect on the degeneration in the liver, kidney and pancreas tissues of streptozotocin (STZ) induced diabetic rats ${ }^{34}$. In an other study, glucose tolerance significantly improved by two flavonoids, rutin and genistein, in STZ induced diabetic rats ${ }^{35}$. It is concluded that dietary soy isoflavones increased insulin secretion and prevented the diabetic cataracts in diabetic rats $^{36}$. Similarly, Lee (2006) showed that soy protein and genistein were seemed to be beneficial for correcting hyperglycemia and preventing diabetic complications in diabetes induced rats ${ }^{37}$. Şakul et al. (2013) demonstrated that antioxidant pyridoindole reversed the effects of diabetes in rat brain and peripheral tissues ${ }^{38}$. The aqueous extract of Anchusa strigosa flowers (250 mg/kg and $500 \mathrm{mg} / \mathrm{kg}$ ) caused a dose-dependent fall in blood glycose, cholesterol and triglyceride levels in STZ induced diabetic rats ${ }^{39}$. In a study with STZ induced diabetes rats, it is concluded that the extract of Beta vulgaris L. var cicla when administered by gavage may reduce glucose levels ${ }^{40}$.

\section{ANTIOXIDANT PHYTOCHEMICALS in DIABETES}

\section{Limonene}

Limonene (p-Mentha-1,8-diene) is a major component of oils obtained from Citrus plants, orange, lemon and grape fruit ${ }^{41,42}$. Limonene is listed in the Code of Federal Regulation as generally recognized as safe (GRAS) for a flavoring agent ${ }^{43}$. It is commonly used as an additive in foods, soaps and perfumes ${ }^{44}$. Die- 
tary intake of limonene varies depending on the intake of foods ${ }^{43}$. It is also shown that it has exerted antiproliferative effects in various cancer cell types ${ }^{45}$, ${ }^{6}$. It has been clinically used to dissolve gallstones and also to prevent gastric diseases ${ }^{43}$.

Glycation inhibitors possessing amino groups could compete to bind to glucose, scavenge dicarbonyls, and chelate metal ions and the structure of limonene precludes such an action. Joglekar et al. (2013) studied the antiglycative properties of limonene and also the interaction of limonene with bovine serum albumin (BSA) and the possible mechanism of inhibition of protein glycation ${ }^{47}$. They found that limonene functioned as a protein glycation inhibitor through a novel mechanism of stabilization of the native protein structure.

In a study with STZ induced diabetic rats, 50, 100 and $200 \mathrm{mg} / \mathrm{kg}$ doses of limonene and $600 \mu \mathrm{g} / \mathrm{kg}$ glibenclamide were administrated for 45 days. It was found that the antidiabetic effect of d-limonene was comparable with glibenclamide and the effect of d-limonene was more pronounced in the doses of $100 \mathrm{mg} / \mathrm{kg}$ body weight than the other two doses ${ }^{48}$. More et al. (2014) have demonstrated that $100 \mu \mathrm{M}$ concentration of limonene demonstrated $85.61 \%$ inhibition of protein glycation while the positive control aminoguanidine demonstrated $88.02 \%$ inhibition at $1 \mathrm{mM}$ concentration in STZ induced diabetic rats ${ }^{49}$. Administration of D-limonene to diabetic rats for 45 days also caused a significant reduction in the levels of lipid peroxidation by-products and an increase in the activities of antioxidant enzymes including SOD, CAT, GSH and glutathione S transferase, when compared with the untreated diabetic group ${ }^{50}$.

\section{Cinnamic Acid}

Cinnamic acid and its derivatives possess a variety of pharmacologic properties such as antioxidant, hepatoprotective, antimalarial and antityrosinase activiti$\mathrm{es}^{51,52,53,54}$. It is a phenolic acid that exist in many fruits, vegetables, and beverages including blueberry, kiwi, cherry, plum, apple, pear, chicory, artichoke, potato, cider and coffee ${ }^{55}$. Most of the studies have focused on the antidiabetic activities of cinnamic acid and its derivates.

Inhibition of $\alpha$-glucosidase may be effective in diabetes therapy. Due to this effect, mammalian a-glucosidase inhibitors from natural sources can be beneficial in the prevention and treatment of diabetes mellitus. Adisakwattana et al. (2009) have demonstrated the a-glucosidase inhibitory activity of cinnamic acid derivates against intestinal sucrase inhibitors ${ }^{56}$. It is showed that Cinnamon extracts $(50,100,150$ and $200 \mathrm{mg} / \mathrm{kg}$ ) which include cinnamic acid significantly, decreased the blood glucose and lipid levels in mice ${ }^{57}$. Ping et al. (2010) have studied the hypoglycemic effect of cinnamon oil which contains water soluble polyphenol type A polymer, cinnemaldehyde and cinnamic acid as active com- 
pounds, in type 2 diabetic animal model ${ }^{58}$. They found that fasting blood glucose concentration was significantly decreased with the $100 \mathrm{mg} / \mathrm{kg}$ group compared to other groups. In addition, they found significant decreases in plasma C-peptide, serum triglyceride, total cholesterol and blood urea nitrogen levels while serum high density lipoprotein (HDL)-cholesterol levels were significantly increased after 35 days. Huang et al. (2009) have reported that caffeic and cinnamic acids improve glucose uptake in TNF- $\alpha$-treated insulin-resistant FL83B ${ }^{59}$. Same group have treated the mouse FL83B cells with TNF- $\alpha$ to induce insulin resistance to evaluate the effect of caffeic and cinnamic acids on glucose metabolism. They found that caffeic and cinnamic acids increased expression of glycogen synthase, whereas the expression of glycogen synthase kinase and phosphorylation of glycogen synthase at Ser641 in insulin-resistant mouse hepatocytes was decreased. The compounds suppressed the expression of hepatic nuclear factor-4 in TNF- $\alpha$-treated mouse FL83B hepatocytes. They concluded that caffeic and cinnamic acids ameliorated glucose metabolism by promoting glycogenesis and inhibiting gluconeogenesis in TNF- $\alpha$-treated insulin-resistant mouse hepatocytes ${ }^{60}$. Rao and Rao (2001) have reported the antihyperglycemic effect of Syzygium alternifolium seeds which contain cinnamic acid ${ }^{61}$. The treatment with $50 \mathrm{mg}$ of the fraction $\mathrm{C}$ (which includes cinnamic acid) $\mathrm{kg}$ b.w/day for 30 days resulted in a significant decrease in the fasting blood glucose levels of diabetic rats. The altered enzyme activities of carbohydrate metabolism in liver and kidney of diabetic rats were significantly reverted to near normal levels by the administration of fraction $\mathrm{C}^{62}$.

\section{Ursolic Acid}

Ursolic acid (3ß-hydroxy-12-urs-12-en-28-oic acid) is a well-known pentacylic triterpene which is commonly used in traditional Chinese medicine. Malus pumila, Ocimum basilicum, Vaccinium spp., Vaccinium macrocarpon, Olea europaea, Origanum vulgare, Rosmarinus officinalis, Salvia and Thymus plants are the main sources of ursolic acid ${ }^{63}$. In recent years, interest in ursolic acid has increased due to its many beneficial effects and low toxicity. Ursolic acid has been used against different diseases including osteoarthritis, rheumatoid arthritis, ulcer, cancer and diabetes ${ }^{64}$. Ursolic acid has been suggested to increase insulin level with the preservation of pancreatic $\beta$-cells and modulate blood glucose level in diabetic mice ${ }^{65}$.

Yin and Chan (2007) have found that oleanolic acid and ursolic acid could inhibit in vitro formation of pentosidine and Ne-(carboxymethyl)lysine (CML) which have been implicated in the pathogenesis of diabetic nephropathy and other diabetic complications ${ }^{66}$. Wang et al. (2010) have demonstrated that ole- 
anolic acid (0.1 and 0.2\%) and ursolic acid (0.1 and 0.2\%) markedly suppressed renal aldose reductase activity and enhanced glyoxalase I activity, which contributed to decrease renal AGEs formation and improve renal functions. The impact of these two triterpenes on mRNA expression of renal aldose reductase and glyoxalase I revealed that the effects of these agents occurred at transcription level. Low-dose ursolic acid (o.01\% in food) administration in STZ induced diabetic mice with for three months, glomerular hypertrophy and type IV collagen accumulation in the kidneys were found to be markedly ameliorated ${ }^{68}$. It is concluded that, ursolic acid significantly inhibited sorbitol dehydrogenase activity as well as aldose reductase activity, and increased glucokinase activity. While decreasing glucose-6-phosphatase activity, it elevated the hepatic glycogen content and lowered the plasma total cholesterol, free fatty acid, and triglyceride concentrations compared with the diabetic control group. It also normalized hepatic triglyceride concentration in the livers of STZ induced diabetic mice ${ }^{69}$. In a study with STZ induced diabetic rats for 16 weeks, ursolic acid treatment prevented biochemical and histopathologic changes in the kidneys associated with diabetes such as alteration in renal function and increased oxidative stress, NF- $\kappa \mathrm{B}$ activity, and P-selectin expression in the kidneys ${ }^{70}$. Similarly, it is found that ursolic acid (0.05\% w/w) improved blood glucose levels, glucose intolerance, and insulin sensitivity compared to the diabetic group in diabetic rats ${ }^{65}$ and at the doses of $0.01 \% \mathrm{w} / \mathrm{w}$ and $0.05 \% \mathrm{w} / \mathrm{w}$, it improved blood glucose, glycosylated hemoglobin, glucose tolerance, insulin tolerance and plasma leptin levels as well as aminotransferase activity in diabetic mice ${ }^{71}$.

\section{CONCLUSION}

Diabetes is affecting a significant proportion of the population worldwide. It affects many organs including pancreas, kidney and liver. The disease is associated with a reduced quality of life and increased risk factors for mortality and morbidity. In diabetes treatment, traditional herbal folk medicines are getting popular. Due to their antioxidant properties, herbal products give positive and promising results. In this review, we demonstrated the antidiabetic activity of different phytochemicals (limonene, cinnamic acid and ursolic acid). The studies about their antidiabetic activity have shown that these phytochemicals may be beneficial in diabetes therapy. But further in vitro and in vivo studies needed to clear up their efficacy, mechanism and toxicity on diabetes treatment.

\section{Author Contributions}

These authors contributed equally. 


\section{REFERENCES}

1. Duckworth, W. C. Hyperglycemia and cardiovascular disease. Curr Atheroscler Rep. 2001, 3, 383-391.

2. Shaw, J. E.; Sicree, R. A. and Zimmet, P. Z. Global estimates of the prevalence of diabetes for 2010 and 2030. Diabetes Res Clin Pr. 2010, 87, 4-14.

3. Shukla, A.; Bukhariya, V.; Mehta, J.; Bajaj, J.; Charde, R.; Charde, M. and Gandhare, B. Herbal remedies for diabetes: an overview. Int J Biomed Adv Res. 2011, 2, 57-68.

4. Chehade, J. M. and Mooradian, A. D. A rational approach to drug therapy of type 2 diabetes mellitus. Drugs. 2000, 60, 95-113.

5. Sheehan, M. T. Current therapeutic options in type 2 diabetes mellitus: a practical approach. Clin Med Res. 2003, 1, 189-200.

6. Moller, D. E. New drug targets for type 2 diabetes and the metabolic syndrome. Nature. 2001, $414,821-827$.

7. Rotenstein, L. S.; Kozak, B. M.; Shivers, J. P.; Yarchoan, M.; Close, J. and Close, K. L. The ideal diabetes therapy: what will it look like? How close are we? Clin Diabetes. 2012, 30, 44-53.

8. Yusuff, K. B.; Obe, O. and Joseph, B. Y. Adherence to anti-diabetic drug therapy and self management practices among type-2 diabetics in Nigeria. Pharm World Sci. 2008, 30, 876-883.

9. Bever, B. O. Oral hypoglycaemic plants in West Africa. J Ethnopharmacol. 1980, 2, 119-127.

10. Andrade-Cetto, A. and Heinrich, M. Mexican plants with hypoglycaemic effect used in the treatment of diabetes. J Ethnopharmacol. 2005, 99, 325-348.

11. Grover, J.; Yadav, S. and Vats, V. Medicinal plants of India with anti-diabetic potential. J Ethnopharmacol. 2002, 81, 81-100.

12. WHO, 2008. Traditional Medicine. <http://www.who.int/mediacentre/factsheets/fs134/ en/> (accessed 08.07.16).

13. WHO Traditional Medicine Strategy 2014-2023. In: World Health Organization (Ed.), WHO Press: Geneva, Switzerland, 2013.

14. Ezuruike, U. F. and Prieto, J. M. The use of plants in the traditional management of diabetes in Nigeria: pharmacological and toxicological considerations. J Ethnopharmacol. 2014, 155, 857-924.

15. Kaleem, M.; Asif, M.; Ahmed, Q. U. and Bano, B. Antidiabetic and antioxidant activity of Annona squamosa extract in streptozotocin-induced diabetic rats. Singapore Med J. 2006, 47, 670.

16. Dyrskog, S. E. U.; Jeppesen, P. B.; Colombo, M.; Abudula, R. and Hermansen, K. Preventive effects of a soy-based diet supplemented with stevioside on the development of the metabolic syndrome and type 2 diabetes in Zucker diabetic fatty rats. Metabolism. 2005, 54, 1181-1188.

17. Bhathena, S. J. and Velasquez, M. T. Beneficial role of dietary phytoestrogens in obesity and diabetes. Am J Clin Nutr. 2002, 76, 1191-1201.

18. Abdollahi, M.; Ranjbar, A.; Shadnia, S.; Nikfar, S. and Rezaiee, A. Pesticides and oxidative stress: a review. Med Sci Monitor. 2004, 10, RA141-RA147.

19. Naziroğlu, M. and Butterworth, P. J. Protective effects of moderate exercise with dietary vitamin $\mathrm{C}$ and $\mathrm{E}$ on blood antioxidative defense mechanism in rats with streptozotocin-induced diabetes. Can J Appl Physiol. 2005, 30, 172-185. 
20. Penckofer, S.; Schwertz, D. and Florczak, K. Oxidative stress and cardiovascular disease in type 2 diabetes: the role of antioxidants and pro-oxidants. J Cardiovasc Nurs. 2002, 16, 68-85.

21. Desco, M.-C.; Asensi, M.; Márquez, R.; Martínez-Valls, J.; Vento, M.; Pallardó, F. V.; Sastre, $\mathrm{J}$. and Viña, J. Xanthine oxidase is involved in free radical production in type 1 diabetes protection by allopurinol. Diabetes. 2002, 51, 1118-1124.

22. Brownlee, M.; Cerami, A. and Vlassara, H. Advanced glycosylation end products in tissue and the biochemical basis of diabetic complications. New Engl J Med. 1988, 318, 1315-1321.

23. Inoguchi, T.; Li, P.; Umeda, F.; Yu, H. Y.; Kakimoto, M.; Imamura, M.; Aoki, T.; Etoh, T.; Hashimoto, T. and Naruse, M. High glucose level and free fatty acid stimulate reactive oxygen species production through protein kinase C--dependent activation of NAD (P) H oxidase in cultured vascular cells. Diabetes. 2000, 49, 1939-1945.

24. Cosentino, F.; Hishikawa, K.; Katusic, Z. S. and Lüscher, T. F. High glucose increases nitric oxide synthase expression and superoxide anion generation in human aortic endothelial cells. Circulation. 1997, 96, 25-28.

25. Armstrong, D. and Al-Awadi, F. Lipid peroxidation and retinopathy in streptozotocin-induced diabetes. Free Radical Biol Med. 1991, 11, 433-436.

26. Rungby, J.; Flyvbjerg, A.; Andersen, H. B. and Nyborg, K. Lipid peroxidation in early experimental diabetes in rats: effects of diabetes and insulin. Acta Endocrinol. 1992, 126, 378-380.

27. Mazzanti, L.; Faloia, E.; Rabini, R. A.; Staffolani, R.; Kantar, A.; Fiorini, R.; Swoboda, B.; de Pirro, R. and Bertoli, E. Diabetes mellitus induces red blood cell plasma membrane alterations possibly affecting the aging process. Clin Biochem. 1992, 25, 41-46.

28. Godin, D. V.; Wohaieb, S. A.; Garnett, M. E. and Goumeniouk, A. Antioxidant enzyme alterations in experimental and clinical diabetes. Mol Cell Biochem. 1988, 84, 223-231.

29. Asayama, K.; Uchida, N.; Nakane, T.; Hayashibe, H.; Dobashi, K.; Amemiya, S.; Kato, K. and Nakazawa, S. Antioxidants in the serum of children with insulin-dependent diabetes mellitus. Free Radical Biol Med. 1993, 15, 597-602.

30. Astaneie, F.; Afshari, M.; Mojtahedi, A.; Mostafalou, S.; Zamani, M. J.; Larijani, B. and Abdollahi, M. Total antioxidant capacity and levels of epidermal growth factor and nitric oxide in blood and saliva of insulin-dependent diabetic patients. Arch Med Res. 2005, 36, 376-381.

31. Chanwitheesuk, A.; Teerawutgulrag, A. and Rakariyatham, N. Screening of antioxidant activity and antioxidant compounds of some edible plants of Thailand. Food Chem. 2005, 92, 491-497.

32. Rahimi, R.; Nikfar, S.; Larijani, B. and Abdollahi, M. A review on the role of antioxidants in the management of diabetes and its complications. Biomed Pharmacother. 2005, 59, 365-373.

33. Larkins, N. and Wynn, S. Pharmacognosy: phytomedicines and their mechanisms. Vet Clin N Am: Small. 2004, 34, 291-327.

34. Arya, A.; Al-Obaidi, M. M. J.; Shahid, N.; Noordin, M. I. B.; Looi, C. Y.; Wong, W. F.; Khaing, S. L. and Mustafa, M. R. Synergistic effect of quercetin and quinic acid by alleviating structural degeneration in the liver, kidney and pancreas tissues of STZ-induced diabetic rats: a mechanistic study. Food Chem Toxicol. 2014, 71, 183-196.

35. Rauter, A. P.; Martins, A.; Borges, C.; Mota-Filipe, H.; Pinto, R.; Sepodes, B. and Justino, J. Antihyperglycaemic and protective effects of flavonoids on streptozotocin-induced diabetic rats. Phytother Res. 2010, 24, S133-S138. 
36. Lu, M.-P.; Wang, R.; Song, X.; Chibbar, R.; Wang, X.; Wu, L. and Meng, Q. H. Dietary soy isoflavones increase insulin secretion and prevent the development of diabetic cataracts in streptozotocin-induced diabetic rats. Nutr Res. 2008, 28, 464-471.

37. Lee, J.-S. Effects of soy protein and genistein on blood glucose, antioxidant enzyme activities, and lipid profile in streptozotocin-induced diabetic rats. Life Sci. 2006, 79, 1578-1584.

38. Şakul, A.; Cumaoğlu, A.; Aydın, E.; Arı, N.; Dilsiz, N. and Karasu, Ç. Age- and diabetes-induced regulation of oxidative protein modification in rat brain and peripheral tissues: Consequences of treatment with antioxidant pyridoindole. Exp Gerontol. 2013, 48, 476-484.

39. Muhammed, A. and Arı, N. Antidiabetic Activity of The Aqueous Extract of Anchusa strigosa Lab in Streptozotocin Diabetic Rats. Int J Pharm. 2012, 2, 445-449.

40. Bolkent, Ş.; Yanardağ, R.; Tabakoğlu-Oğuz, A.; Özsoy-Saçan, Ö. Effects of chard (Beta vulgaris L. var. cicla) extract on pancreatic B cells in streptozotocin-diabetic rats: a morphological and biochemical study. J Ethnopharmacol. 2009, 14, 15-22.

41. Arruda, D. C.; Miguel, D. C.; Yokoyama-Yasunaka, J. K.; Katzin, A. M. and Uliana, S. R. Inhibitory activity of limonene against Leishmania parasites in vitro and in vivo. Biomed Pharmacother. 2009, 63, 643-649.

42. Del Toro-Arreola, S.; Flores-Torales, E.; Torres-Lozano, C.; Del Toro-Arreola, A.; TostadoPelayo, K.; Ramirez-Dueñas, M. G. and Daneri-Navarro, A. Effect of D-limonene on immune response in BALB/c mice with lymphoma. Int Immunopharmacol. 2005, 5, 829-838.

43. Sun, J. D-Limonene: safety and clinical applications. Altern Med Rev. 2007, 12, 259.

44. Whysner, J. and Williams, G. M. d-Limonene mechanistic data and risk assessment: absolute species-specific cytotoxicity, enhanced cell proliferation, and tumor promotion. Pharmacol Ther. 1996, 71, 127-136.

45. Swenberg, J. A.; Short, B.; Borghoff, S.; Strasser, J. and Charbonneau, M. The comparative pathobiology of a2u-globulin nephropathy. Toxicol Appl Pharmacol. 1989, 97, 35-46.

46. Crowell, P. L.; Kennan, W. S.; Haag, J. D.; Ahmad, S.; Vedejs, E. and Gould, M. N. Chemoprevention of mammary carcinogenesis by hydroxylated derivatives of d-limonene. Carcinogenesis. 1992, 13, 1261-1264.

47. Joglekar, M. M.; Panaskar, S. N.; Chougale, A. D.; Kulkarni, M. J. and Arvindekar, A. U. A novel mechanism for antiglycative action of limonene through stabilization of protein conformation. Mol Biosyst. 2013, 9, 2463-2472.

48. Murali, R. and Saravanan, R. Antidiabetic effect of d-limonene, a monoterpene in streptozotocin-induced diabetic rats. Biomed Prevent Nutr. 2012, 2, 269-275.

49. More, T. A.; Kulkarni, B. R.; Nalawade, M. L. and Arvindekar, A. U. Antidiabetic Activity of Linalool and Limonene in Streptozotocin-Induced Diabetic Rat: A Combinatorial Therapy Approach. Int J Pharm Pharm Sci. 2014, 6, 159-163.

50. Murali, R.; Karthikeyan, A. and Saravanan, R. Protective Effects of d-Limonene on Lipid Peroxidation and Antioxidant Enzymes in Streptozotocin-Induced Diabetic Rats. Basic Clin Pharmacol Toxicol. 2013, 112, 175-181.

51. Lee, E. J.; Kim, S. R.; Kim, J. and Kim, Y. C. Hepatoprotective phenylpropanoids from Scrophularia buergeriana roots against $\mathrm{CCl}_{4}$-induced toxicity: action mechanism and structure-activity relationship. Planta Med. 2002, 68, 407-411. 
52. Lee, H.-S. Tyrosinase inhibitors of Pulsatilla cernua root-derived materials. J Agricul Food Chem. 2002, 50, 1400-1403.

53. Wiesner, J.; Mitsch, A.; Wißner, P.; Jomaa, H. and Schlitzer, M. Structure-activity relationships of novel anti-malarial agents. Part 2: cinnamic acid derivatives. Bioorgan Med Chem Lett. 2001, 11, 423-424.

54. Natella, F.; Nardini, M.; Di Felice, M. and Scaccini, C. Benzoic and cinnamic acid derivatives as antioxidants: structure-activity relation. J Agricull Food Chem. 1999, 47, 1453-1459.

55. Manach, C.; Scalbert, A.; Morand, C.; Rémésy, C. and Jiménez, L. Polyphenols: food sources and bioavailability. American J Clin Nutr. 2004, 79, 727-747.

56. Adisakwattana, S.; Chantarasinlapin, P.; Thammarat, H. and Yibchok-Anun, S. A series of cinnamic acid derivatives and their inhibitory activity on intestinal $\alpha$-glucosidase. J Enzym Inhib Med Ch. 2009, 24, 1194-1200.

57. Kim, S. H.; Hyun, S. H. and Choung, S. Y. Anti-diabetic effect of cinnamon extract on blood glucose in db/db mice. J Ethnopharmacol. 2006, 104, 119-123.

58. Ping, H.; Zhang, G. and Ren, G. Antidiabetic effects of cinnamon oil in diabetic KK-Ay mice. Food Chem Toxicol. 2010, 48, 2344-2349.

59. Huang, D.-W.; Shen, S.-C. and Wu, J. S.-B. Effects of caffeic acid and cinnamic acid on glucose uptake in insulin-resistant mouse hepatocytes. J Agricult Food Chem. 2009, 57, 7687-7692.

6o. Huang, D.-W. and Shen, S.-C. Caffeic acid and cinnamic acid ameliorate glucose metabolism via modulating glycogenesis and gluconeogenesis in insulin-resistant mouse hepatocytes. J Funct Foods. 2012, 4, 358-366.

61. Rao, B. K. and Rao, C. A. Hypoglycemic and antihyperglycemic activity of Syzygium alternifolium (Wt.) Walp. seed extracts in normal and diabetic rats. Phytomedicine. 2001, 8, 88-93.

62. Kasetti, R. B.; Rajasekhar, M. D.; Kondeti, V. K.; Fatima, S. S.; Kumar, E. G. T.; Swapna, S.; Ramesh, B. and Rao, C. A. Antihyperglycemic and antihyperlipidemic activities of methanol: water (4: 1) fraction isolated from aqueous extract of Syzygium alternifolium seeds in streptozotocin induced diabetic rats. Food Chem Toxicol. 2010, 48, 1078-1084.

63. Ikeda, Y.; Murakami, A. and Ohigashi, H. Ursolic acid: An anti-and pro-inflammatory triterpenoid. Mol Nutr Food Res. 2008, 52, 26-42.

64. Kim, K.-A.; Lee, J.-S.; Park, H.-J.; Kim, J.-W.; Kim, C.-J.; Shim, I.-S.; Kim, N.-J.; Han, S.-M. and Lim, S. Inhibition of cytochrome $\mathrm{P} 450$ activities by oleanolic acid and ursolic acid in human liver microsomes. Life Sci. 2004, 74, 2769-2779.

65. Jang, S.-M.; Yee, S.-T.; Choi, J.; Choi, M.-S.; Do, G.-M.; Jeon, S.-M.; Yeo, J.; Kim, M.-J.; Seo, K.-I. and Lee, M.-K. Ursolic acid enhances the cellular immune system and pancreatic $\beta$-cell function in streptozotocin-induced diabetic mice fed a high-fat diet. Int Immunopharmacol. 2009, 9, 113-119.

66. Yin, M.-C. and Chan, K.-C. Nonenzymatic antioxidative and antiglycative effects of oleanolic acid and ursolic acid. J Agricul Food Chem. 2007, 55, 7177-7181.

67. Wang, Z.H.; Hsu, C.C.; Huang, C.N. and Yin, M.C. Anti-glycative effects of oleanolic acid and ursolic acid in kidney of diabetic mice. Eur J Pharmacol. 2010, 628, 258-260.

68. Zhou, Y.; Li, J.-S.; Zhang, X.; Wu, Y.-J.; Huang, K. and Zheng, L. Ursolic acid inhibits early lesions of diabetic nephropathy. Int J Mol Med. 2010, 26, 565. 
69. Jang, S.-M.; Kim, M.-J.; Choi, M.-S.; Kwon, E.-Y. and Lee, M.-K. Inhibitory effects of ursolic acid on hepatic polyol pathway and glucose production in streptozotocin-induced diabetic mice. Metabolism. 2010, 59, 512-519.

70. Ling, C.; Jinping, L.; Xia, L. and Renyong, Y. Ursolic acid provides kidney protection in diabetic rats. Curr Ther Res. 2013, 75, 59-63.

71. Lee, J.; Yee, S.-T.; Kim, J.-J.; Choi, M.-S.; Kwon, E.-Y.; Seo, K.-I. and Lee, M.-K. Ursolic acid ameliorates thymic atrophy and hyperglycemia in streptozotocin-nicotinamide-induced diabetic mice. Chem-Biol Interact. 2010, 188, 635-642.

(Received o4 August 2016; accepted 29 August 2016) 